SECTION 21. Pedagogy. Psychology. Innovations in the field of education.

Aigul Zhorabekovna Tulegenova

Senior lecturer of the Department of History of Kazakhstan and law, basics of economics Arkalyk State Pedagogical Institute named after I.Altynsarin, Kazakhstan

Nazira Izbastyyevna Yessimkhanova Master of pedagogical sciences Senior lecturer of the Department of History of Kazakhstan and law, basics of economics Arkalyk State Pedagogical Institute named after I.Altynsarin, Kazakhstan arizan79@inbox.ru

\title{
USING OF TEACHING E-LERNING TOOLS IN TEACHING HISTORY
}

Abstract: In the given article the urgency and the efficiency of use of electronic textbooks in teaching History are considered as the priority direction to modernizations of the modern Kazakhstan education. Practical use of electronic textbooks raises the efficiency and quality of the process of the education, actuates cognitive activity of the students to account of the computer visualization, deepens the relationship between the subjects, individualizes and differentiates the process of the education, promotes the formation of culture to school activity, informational culture of trained and training.

Key words: System of education, methods of teaching and E-learning tools.

\section{УДК 372.893}

\section{ИСПОЛЬЗОВАНИЕ ЭЛЕКТРОННЫХ СРЕДСТВ ОБУЧЕНИЯ В ПРЕПОДАВАНИИ ИСТОРИИ}

Аннотация: В данной статье рассмотрень основные приоритеть развития системы образования Республики Казахстан, эффективность использования электронных средств обучения в преподавании истории.

Ключевые слова: система образования, методы обучения и электронные средства обучения.

На современном этапе в Казахстане реализуется Государственная программа развития образования, нацеленная на кардинальную модернизацию всех уровней образования - от дошкольного до высшего [1].

Общей целью образовательных реформ является адаптация системы образования к новой социально-экономической среде. Президентом Казахстана была также поставлена задача о вхождении нашей страны в число 30-ти самых развитых государств мира.

Совершенствование системы образования играет важную роль в достижении этой цели. Международный опыт подтверждает, что инвестиции в человеческий капитал, и, в частности, в образование, начиная с раннего детства до зрелого возраста, способствуют существенным отдачам для экономики и общества. Данные принципы определены как цель государственной программы развития образования Республики Казахстан на 2011-2020 годы, а это повышение конкурентоспособности образования, развитие человеческого капитала путем обеспечения доступности качественного образования для устойчивого роста экономики [2].

А для этого создаются равные возможности для получения доступного и качественного образования. Если за последние 15 лет расходы на образование выросли в 
9,5 раза, то количество грантов для получения высшего образования за последние 12 лет увеличилось на $182 \%$ [1].

В своем выступлении перед студентами с лекцией «Казахстан на пути к обществу знаний» от 5 сентября 2012 года Президент Республики Казахстан Н.А.Назарбаев отметил: «Мы движемся к постиндустриальному миру, в котором правит триада «образование наука - инновации». В связи с этим, качественное образование, которое Вы получаете, является лишь стартовым интеллектуальным капиталом. Вам нужно непрерывно работать над собой, повышать свое образование, профессиональные компетенции» [3].

Образование признано одним из важнейших приоритетов долгосрочной программы «Стратегия «Казахстан - 2050»: новый политический курс состоявшегося государства», где было сказано, что в процессе модернизации методик преподавания и активного развития онлайн-системы образования, мы должны интенсивно внедрять инновационные методы, решения и инструменты в отечественную систему образования, включая дистанционное обучение и обучение в режиме онлайн, доступные для всех желающих [1].

Внедрение электронной системы обучения (e-learning) дает возможность повысить эффективность, качество и результативность обучения. Поэтому необходимо внедрять передовые технологии и методики, новые способы передачи знаний и развития мотивации обучающихся, направленные на формирование познавательной активности учащихся. Самораскрытие, самовоспитание, самоактивность и самореализация личности в жизни становятся ориентиром организации педагогического процесса [4].

Инновационные методы обучения, основанные на активных, самостоятельных формах приобретения знаний и работе с информацией, вытесняют демонстрационные и иллюстративно-объяснительные методы, широко используемые традиционной методикой обучения, ориентированной, в основном, на коллективное восприятие информации [5].

Одним из наиболее популярных компьютерных средств обучения стали электронные учебники, позволяющие реализовать функции обучения, самообучения, демонстрации изучаемого материала, тренировки в применении изученного материала, контроля и самоконтроля, систематизации усвоенных знаний и являющиеся таким образом многоцелевым средством обучения [6]. Электронный учебник ставится в один ряд с автоматизированными обучающими системами. Поэтому, использование электронных средств обучения и введение их в учебный процесс сегодня особенно актуальны.

История - как учебная дисциплина составляет стержень всех гуманитарных и обществоведческих курсов как в школе, так и в ВУЗе. Данная дисциплина отражает весь опыт человечества [7].

Главной задачей использования электронных учебников по истории является интенсификация учебного процесса, повышения его эффективности и качества [8].

Одним из приоритетных направлений процесса информатизации современного общества является информатизация образования - процесс обеспечения сферы образования методологией и практикой разработки и оптимального использования новых информационных технологий, ориентированных на реализацию основных целей обучения и воспитания.

Этот процесс инициирует преподавателя высшей школы на выполнение следующих обязательных условий:

1) совершенствование методологии и стратегии отбора содержания, методов и организационных форм обучения, воспитания, соответствующих задачам развития личности обучаемого в современных условиях информатизации общества;

2) создание методических систем обучения, ориентированных на развитие интеллектуального потенциала обучаемого, на формирование умений самостоятельно 
приобретать знания, осуществлять информационно - учебную, научно исследовательскую, самостоятельную деятельность по обработке информации;

3) создание и использование компьютерных тестирующих, диагностирующих методик контроля и оценки уровня знаний обучаемых.

Электронные средства обучения, обладающие повышенной мультимедийностью и динамичностью, способствует выработке фрактальной методологии, переходу к образному многомерному мышлению.

Электронный учебник - компьютерное, программное средство, предназначенное, в первую очередь, для предъявления новых исторических источников, дополняющей печатные издания, служащее для группового, индивидуального или индивидуализированного обучения и позволяющее контролировать полученные знания и умения обучаемых. Являясь современным средством обучения ЭУ существенно повышает качество и эффективность обучения, мотивацию студентов и оптимизирует деятельность преподавателя [9].

Электронные учебники по историческим дисциплинам применимы не только в качестве средства обучения, совершенствующего процесс преподавания, безусловно повышающего его эффективность и результативность, но и зарекомендовали себя в качестве:

1) инструмента познания окружающей действительности и самопознания;

2) средства развития личности обучаемого;

3) объекта изучения (например, в рамках освоения курса истории древнего мира);

4) средства информационно - методического обеспечения;

5) средства коммуникаций в целях распространения передовых педагогических технологий;

6) средства автоматизации процессов контроля, коррекции результатов учебной деятельности;

7) средства организации самостоятельной, научно-исследовательской работы и интеллектуального досуга студентов.

Особого внимания заслуживает описание возможностей электронных учебников, использование которых создает предпосылки для интенсификации образовательного процесса по истории:

- незамедлительная обратная связь;

- компьютерная визуализация учебной информации об объектах или закономерностях исторических процессов, явлений, как реально протекающих, так и «виртуальных»;

- архивное хранение достаточно больших объемов информации с возможностью ее передачи, а также легкого доступа и обращения пользователя;

- автоматизация процессов информационно-методического обеспечения, организационного управления учебной деятельностью и контроля за результатами усвоения.

Возможность электронного учебника существенным образом влияет на развитие личности обучаемого, качественно иную подготовку специалистов новой формации и обеспечивает:

- развитие мышления, (например, наглядно-действенного, наглядно-образного, интуитивного, творческого, теоретического);

- эстетическое воспитание (например, за счет использования возможностей компьютерной графики, технологии Мультимедиа);

- развитие коммуникативных способностей;

- формирование умений принимать оптимальное решение или предлагать варианты решения в сложной ситуации.

- развитие умений осуществлять научно-исследовательскую деятельность; 
- формирование информационной компетентности и информационной культуры.

Анализируя теоретические и практические аспекты по методике использования электронного учебника на занятиях по истории, можно сформулировать следующие выводы:

- внедрение в процесс обучения истории электронного учебника позволяет формировать высокую познавательную активность студентов, их самостоятельность в процессе образовательного государственного стандарта специальности «История»;

- электронный учебник позволяет студентам создавать собственные мультимедийные проекты, интерактивные доклады, рефераты, глоссарий, хронологические таблицы, схемы и карты;

- электронный учебник является основным образовательным электронным изданием, созданным на высоком научном и методическом уровне [10].

Практическое использование электронных учебников повышает эффективность и качество процесса обучения, активизирует познавательную деятельность студентов за счет компьютерной визуализации, углубляет межпредметные связи, индивидуализирует и дифференцирует процесс обучения, способствует формированию культуры учебной деятельности, информационной культуры обучаемого и обучающего.

\section{References:}

1. Послание Президента Республики Казахстан-Лидера нации Н. Назарбаева народу Казахстана «Стратегия «Казахстан - 2050»: новый политический курс состоявшегося государства».

2. Указ Президента Республики Казахстан от 7 декабря 2010 года № 1118 «Государственная программа развития образования Республики Казахстан на 20112020 годы».

3. Казахстан на пути к обществу знаний. Выступление Президента Н.Назарбаева перед студентами Назарбаев Университета. //Казахстанская правда. 06.09.2012. № 299-300.

4. Лессер С.К. Использование ИКТ (информационно-коммуникационных технологий) в преподавании исторических и общественных дисциплин //История Казахстана: преподавание в школах и ВУЗах. - 2011. - № 3. - С.22

5. Короткова М.В. Наглядность на уроках истории. -М., 2000.

6. Степанищев А.Т. Методика преподавания и изучения истории. - М.,2002.

7. Инструктивно-методическое письмо «Об особенностях преподавания основ наук в средних образовательных учебных заведениях Республики Казахстан в 2013-2014 учебном году».

8. Студеникин В.Г. Методика преподавания истории в школе. -Москва, 2004.

9. Роберт И.В. Современные информационные технологии в образовании. -М: ШколаПресс, 2007.

10. Акназаров Б.З. Методическая разработка к практическим и лабораторным занятиям по методике преподавания истории Казахстана. -Алматы, 1997. 